www.uoc.edu/idp

ARTÍCULO

\title{
Las intimaciones judiciales en la Ley de secretos empresariales
}

\author{
Consuelo Ruiz de la Fuente \\ Universidad Autónoma de Barcelona
}

Fecha de presentación: febrero de 2020

Fecha de aceptación: julio de 2020

Fecha de publicación: marzo de 2021

\begin{abstract}
Resumen
Con la Ley 1/2019 el legislador español transpone la Directiva Europea 2016/943 y da la necesaria protección a los secretos empresariales. Se trata de aportar seguridad jurídica en un ámbito delicado donde la clave está en ser eficaces. Poco se logra si se prevé la protección del secreto empresarial pero no se establecen medidas eficaces para que este secreto siga siéndolo, y en caso de vulneración, garantizar la adopción de todas las medidas necesarias para recomponer la situación hasta antes de aquella vulneración, minimizando las consecuencias negativas ocasionadas al titular del secreto que haya sido perjudicado, e incluso indemnizarlo debidamente por los daños sufridos. Por último, también se deben adoptar las medidas necesarias para evitar que dicha vulneración se repita en el futuro. Precisamente para maximizar la eficacia de la protección, surge la intimación judicial como una herramienta legal ágil, económica y disponible para los tribunales, que garantiza las acciones civiles previstas en la Ley 1/2019 y el cumplimiento de las resoluciones judiciales adoptadas en este ámbito, cuyo fin último es mejorar las condiciones, el marco para el desarrollo y la explotación de la innovación y la transferencia de conocimientos.
\end{abstract}

\section{Palabras clave}

secreto empresarial, indemnización coercitiva, intimación judicial, ejecución civil 


\title{
Judicial orders in the trade secrets law
}

\begin{abstract}
With Law 1/2019, the Spanish legislator transposes EU Directive 2016/943, and gives the necessary protection to trade secrets, in order to contribute to legal certainty in a delicate field, where the key is effectiveness. The legal protection of the trade secret is of little use if it is not accompanied by effective measures so that this secret is kept, and in case of violation, ensuring the adoption of all the necessary measures in order to re-establish the situation to that which existed before the violation, minimising the negative consequences that the said violation has occasioned to the prejudiced owner of the secret, and also compensating him/her properly for the damages already occasioned. Finally, the necessary measures must also be adopted to prevent the said violation from happening again in the future. In order to maximise the efficacy of the protection, judicial orders arise as an agile and inexpensive legal tool, available to the Courts, that allows them to guarantee the civil actions provided in Law 1/2019 and secures compliance with the judicial decisions adopted in this field, the ultimate goal being to improve conditions, the framework for the development and use of innovation, and the transfer of knowledge.
\end{abstract}

\section{Keywords}

trade secrets, coercive compensation, judicial orders, civil enforcement 
1. La nueva regulación de la intimación judicial en materia de secretos empresariales

En materia de protección de secretos empresariales, la Unión Europea aprobó la Directiva (UE) 2016/943 del Parlamento Europeo y Consejo de 8 de junio de 2016, con el objeto de proteger los secretos empresariales contra su obtención, utilización o revelación ilícitas por terceros. La directiva pretende armonizar la legislación de los Estados miembros con el fin de establecer un nivel suficiente y comparable de reparación en todo el mercado interior en caso de apropiación indebida de secretos empresariales.

Es una legislación que nace con una clara vocación de eficacia. La propia exposición de motivos de la directiva establece que «La eficacia de las medidas, procedimientos y recursos a disposición de los poseedores de secretos comerciales podría verse mermada en caso de incumplimiento de las correspondientes resoluciones adoptadas por las autoridades judiciales competentes. Por este motivo, es necesario garantizar que dichas autoridades dispongan de poderes sancionadores adecuados». Tratándose de derechos inmateriales, es lógico que tengan preponderancia las instituciones procesales que deben garantizarlos.

Siguiendo esta senda, en España se dicta la Ley 1/2019 de 20 de febrero, que regula el secreto empresarial. En la exposición de motivos, el legislador nacional reconoce que la falta de instrumentos jurídicos eficaces y comparables para la protección de los secretos empresariales menoscaba los incentivos para emprender actividades asociadas a la innovación e impiden que los secretos empresariales puedan liberar su potencial como estímulos de crecimiento económico y del empleo. Por lo tanto, se trata de garantizar que los secretos empresariales se encuentren protegidos de manera adecuada y que se mejoren las condiciones y el marco para el desarrollo y la explotación de la innovación y la transferencia de conocimientos. Prácticamente la mitad de la nueva regulación está conformada por normas procesales.

El secreto empresarial ${ }^{1}$ es cualquier información o conocimiento, incluido el tecnológico, científico, industrial, comercial, organizativo o financiero que reúna las siguientes condiciones (art. 1 Ley 1/2019):

a) Ser secreto, en el sentido de que, en su conjunto o en la configuración y reunión precisas de sus componentes, no es generalmente conocido por las personas pertenecientes a los círculos en que normalmente se utilice el tipo de información o conocimiento en cuestión, ni fácilmente accesible para ellas;

b) tener un valor empresarial, ya sea real o potencial, precisamente por ser secreto; y

c) haber sido objeto de medidas razonables, por parte de su titular, para mantenerlo en secreto.

Algunos ejemplos de informaciones que puedan estar protegidas por secretos empresariales son: fórmulas químicas o matemáticas; procesos de fabricación; información sobre organización o mantenimiento de un producto o una planta industrial; un producto y sus especificaciones técnicas; información comercial, financiera y organizativa; estrategias, planes de negocio y marketing; información sobre clientes y proveedores; fuentes de financiación, contratos y costes de producción².

A la hora de proteger la defensa de los secretos empresariales, el legislador ha optado por convertir en acciones lo que en la Directiva 2016/943 eran los distintos tipos de requerimientos y medidas correctivas por la infrac-

1. La doctrina considera un acierto que la ley se refiera a «secretos empresariales» y no a «secretos comerciales» como lo hace la directiva, ya que el calificativo comercial deja fuera el secreto industrial. Por eso es más adecuado referirse al «secreto empresarial», que comprende tanto el secreto comercial como el secreto industrial, y que es equiparable al término anglosajón de know-how. Ver García Vidal (2019, pág. 2).

2. Protocolo de Protección del Secreto Empresarial en los Juzgados Mercantiles. Sección de Derecho de la Competencia, Tribunal Mercantil de Barcelona de 2019: https://www.oepm.es/export/sites/oepm/comun/documentos_relacionados/Noticias/2019/2019_11_22_Protocolo_Proteccion_Secreto_Empresarial_en_los_JM.pdf 
la infracción de un secreto empresarial ${ }^{3}$, y siguiendo al modelo anglosajón en esta materia, se configura en gran medida la posición jurídica del «poseedor» del secreto a través de las acciones ejercitables ${ }^{4}$. Se contemplan una serie de acciones civiles dirigidas a aquellas personas físicas o jurídicas que vulneren dichos secretos, o incluso a terceros que, de buena fe, hubieran obtenido acceso al secreto empresarial directa o indirectamente de un infractor. Dichas acciones civiles, previstas por el art. 9 de la Ley 1/2019, son:

a) La declaración de la violación del secreto empresarial.

b) La cesación o, en su caso, la prohibición de los actos de violación del secreto empresarial.

c) La prohibición de fabricar, ofrecer, comercializar o utilizar mercancías infractoras o de su importación, exportación o almacenamiento con dichos fines.

d) La aprehensión de las mercancías infractoras, incluida la recuperación de las que se encuentren en el mercado, y de los medios destinados únicamente a su producción, siempre que tal recuperación no menoscabe la protección del secreto comercial en cuestión, con una de las siguientes finalidades: su modificación para eliminar las características que determinen que las mercancías sean infractoras, o que los medios estén destinados únicamente a su producción, su destrucción o su entrega a entidades benéficas.

e) La remoción, que comprende la entrega al demandante de la totalidad o parte de los documentos, objetos, materiales, sustancias, ficheros electrónicos y cualesquiera otros soportes que contengan el secreto empresarial, y en su caso su destrucción total o parcial.

f) La atribución en propiedad de las mercancías infractoras al demandante, en cuyo caso el valor de las mercancías entregadas podrá imputarse al importe de la indemnización de daños y perjuicios debida, sin perjuicio de la subsistencia de la responsabilidad del infractor en lo que se refiere a la cuantía indemnizatoria que exceda del referido valor. Si el valor de las mercancías excede del importe de la indemnización, el demandante deberá compensarlo a la otra parte.

g) La indemnización de los daños y perjuicios, si ha intervenido dolo o culpa del infractor, que será adecuada respecto de la lesión realmente sufrida como consecuencia de la violación del secreto empresarial.

h) La publicación o difusión completa o parcial de la sentencia, que deberá preservar en todo caso la confidencialidad del secreto empresarial en los términos del art. 15 de esta ley.

Como se puede observar, varias de dichas acciones consisten esencialmente en obligaciones de dar, hacer o no hacer a cargo del demandado. Lo que realmente busca el legislador con esta norma es precisamente que el infractor cese en la vulneración de los derechos protegidos por el secreto empresarial; por tanto, la sentencia va a contener una orden judicial en este sentido, y para que esta sea realmente efectiva, deberá adoptar la forma de una intimación judicial.

Como parte de sus poderes de dirección del proceso, el órgano judicial está facultado para emitir intimaciones judiciales con el fin de compeler a partes o terceros a cumplir con sus obligaciones procesales y colaborar así con la buena marcha del proceso. En anteriores trabajos, hemos definido la intimación judicial como aquel acto de comunicación del órgano jurisdiccional, dirigida a cualquier persona, con el objeto de compelerla a la realización o abstención de determinada conducta, informándole también de las consecuencias jurídicas de su inobservancia, cuando sea necesaria su colaboración en un proceso determinado ${ }^{5}$. Así, estas resultan ser una herramienta disponible para los órganos jurisdiccionales, e idónea para hacer cumplir las obligaciones a cargo del

\footnotetext{
3. El antecedente directo lo encontramos en el art. 12 de la Directiva Europea 2016/943 UE, que establece los requerimientos y medidas coercitivas que los Estados miembros garantizarán que puedan adoptarse cuando se haya dictado una resolución judicial por la que se declare vulnerado un secreto empresarial.
}

4. En este sentido, Arroyo Aparicio (2019, pág. 5) considera que la parte más relevante del texto europeo viene integrada por el requerimiento dirigido a los Estados miembros a fin de garantizar el ejercicio de las acciones civiles pertinentes.

5. Ver Ruiz de la Fuente (2011, pág. 64 y sigs). 
condenado. Son herramientas contenidas en la ley, y en el ámbito de los secretos empresariales, presentan caracteres específicos por las medidas concretas que pueden acompañarla.

En efecto, para reforzar el cumplimiento de estas pretensiones, el legislador establece que en los supuestos que van desde las letras a) a la f) citadas anteriormente, el juez establecerá en la sentencia una indemnización coercitiva por día transcurrido, hasta que se produzca el cumplimiento de la propia sentencia.

La normativa comunitaria que se está transponiendo no tiene una institución equivalente, sino que únicamente exige, para el caso de incumplimiento de las medidas impuestas en sentencia, multas coercitivas periódicas que sean «efectivas, proporcionadas y disuasorias» (art. 16 Directiva 2016/943). Esta previsión presenta algunos aspectos novedosos que se deducen de su propio nombre, al constituir un híbrido entre 1) la multa coercitiva que puede acompañar a una intimación judicial y 2) la indemnización de los perjuicios que el favorecido por la intimación sufre por su incumplimiento. Al ser la directiva solo de mínimos, nada impide que el legislador español prevea una indemnización coercitiva que en sí puede reforzar su efectividad.

La aplicación de la indemnización coercitiva consiste en una medida de especial importancia para doblegar voluntades renuentes al cumplimiento de una condena de cese en las acciones por vulneración de secreto empresarial. La imposición de una indemnización por cada día que pase sin que se dé cumplimiento a la condena refuerza la eficacia de la sentencia y garantiza el principio de seguridad jurídica. Aún habrá que esperar para saber cómo aplicarán los tribunales dicha norma. La doctrina, por su parte, en la voz de Gascón Inchausti, considera que la adecuada aplicación de la norma va a requerir que los jueces y abogados no tengan reparos en desenvolverse con aplomo en entornos caracterizados por la presencia de conceptos jurídicos indeterminados, como la razonabilidad, proporcionalidad y adecuación, lo que resulta necesario para abordar de forma eficaz una realidad compleja y a veces poco nítida6.

\section{Particularidades de las intimaciones judiciales en materia de secretos empresariales}

La intimación judicial para la protección de secretos empresariales tiene la particularidad de que por regla general estará contenida, por mandato legal expreso, en la propia sentencia. Por lo que debemos partir del supuesto de que solo tendrá lugar si hay sentencia que condene al demandado por vulneración del secreto empresarial. No obstante, en atención a que la intimación formará parte del contenido de la sentencia, también se podría pedir como medida cautelar, precisamente para asegurar la eficacia de la propia sentencia, siempre que concurran los requisitos propios de estas medidas. En definitiva, si la parte lo pide, ya que es necesaria instancia de parte (art. 721 LEC), y el tribunal lo considera apropiado, antes de conocer el fondo del asunto podrá dictar como medida cautelar que el presunto infractor se abstenga de seguir realizando determinada actividad o de difundir determinada información, entre otras disposiciones.

Por otra parte, esta intimación no puede ser incorporada de oficio a la sentencia, sino que debe haber sido pedida por la actora en su demanda. Es consecuencia lógica de la aplicación del principio dispositivo que rige en este ámbito. Entendemos que no podría ser solicitada en un momento posterior, por el límite establecido en el art. 412.1 LEC. Solo podría dejarse para un momento posterior alguna petición complementaria, como la alegación de algún detalle referente al importe de la indemnización coercitiva o a la duración o extensión de la intimación judicial, pero en ningún caso se podrá alterar sustancialmente las pretensiones de la demanda.

Por lo tanto, para que exista intimación, deben concurrir los siguientes presupuestos:

1) Que se hubieren interpuesto alguna de las acciones civiles en defensa de los secretos empresariales enumerados en las letras a) a la f) del art. 9.1 de la Ley 1/2019.

2) Que el actor pida expresamente al tribunal la intimación al demandado y la imposición de una indemnización coercitiva por incumplimiento.

6. Gascón (2018, pág. 2). 
3) Que exista sentencia de condena en el proceso en cuestión, sin perjuicio de que pueda ser adoptada también mediante auto de medidas cautelares.

Si concurren estos presupuestos, entendemos que el tribunal deberá incluir, en todo caso, la correspondiente intimación judicial en su sentencia, ya que el legislador no parece preverlo como una facultad del tribunal, atendida la literalidad del precepto que señala que, si se dan los supuestos, «la sentencia fijará...» (art. 9.6 Ley 1/2019).

Las intimaciones judiciales estarán vigentes desde que las dicte el órgano judicial, y serán exigibles para el demandado desde que le sea notificada la sentencia o auto de medidas cautelares en la que está contenida aquella intimación. Si la intimación contiene un plazo para el cumplimiento, serán exigibles desde que se cumpla dicho plazo.

Hay que tener en cuenta que no hace falta esperar a la ejecución para que el contenido de la orden judicial sea exigible, ni tampoco esperar que exista un incumplimiento posterior a la sentencia para reiterar el requerimiento. Esto también es predicable de las sentencias no firmes que estimen las acciones indicadas en la medida en que los pronunciamientos, por su naturaleza de condena, podrán por lo general ser objeto de ejecución provisional (art. 456.3 y 524 LEC). Precisamente, la intención del legislador es proteger el secreto empresarial desde que es declarada su existencia y vulneración en la sentencia, por lo que la propia sentencia judicial ha de contener una intimación judicial completa que ordene en forma precisa las acciones o prohibiciones que debe cumplir el requerido condenado, y también los apercibimientos o consecuencias que puede conllevar el incumplimiento de esta.

Lo que se busca con la intimación judicial es disuadir al infractor para que se abstenga de seguir vulnerando el secreto empresarial o, en su caso, reponer las actuaciones fraudulentas. Por ejemplo, si se impone la aprehensión de las mercancías fraudulentas o la entrega al actor de documentos o soportes que contengan el secreto empresarial. Excepcionalmente, si se adopta como medida cautelar, hay que recordar que su entrada en vigor quedará supeditada a la previa prestación de la caución que pueda haber fijado el juez (art. 737 LEC).
Por otra parte, las medidas de cesación y prohibición, y la consiguiente indemnización coercitiva, dejarán de tener efecto si la información en cuestión deja de tener el carácter de secreto empresarial por causas no atribuibles directa o indirectamente al infractor condenado. No obstante, en este supuesto, es el infractor quien deberá solicitar que las medidas adoptadas se extingan o queden sin efecto. Esta medida venía impuesta por la Directiva comunitaria en su art. 13.2. Esta pretensión deberá instarse por los cauces de un nuevo procedimiento declarativo, porque la ley española no establece ninguna solución procesal específica para dejarla sin efecto, aunque hubiese sido deseable que lo hiciera. Solo para el caso de que se hubieran adoptado con carácter cautelar, la ley española expresamente prevé el posible alzamiento inmediato de las medidas cautelares por este motivo (art. 24 Ley 1/2019).

\section{Estructura de la intimación judicial en materia de secretos empresariales}

Las intimaciones judiciales deberán tener una estructura con un contenido mínimo del cual no se podrá prescindir. En efecto, la intimación judicial es una institución procesal compleja, compuesta por una serie de elementos definitorios objetivos y subjetivos, así como de efectos procesales y extraprocesales. El legislador no siempre es lo suficientemente explícito ni regula la institución de forma sistemática, por lo que se hace necesario su sistematización y explicitación. La estructura que proponemos se fundamenta en nuestras investigaciones previas sobre la institución ${ }^{7}$. A continuación, analizamos pues la estructura de las intimaciones judiciales en materia de secretos empresariales y su contenido mínimo.

\subsection{Requerimiento y destinatario}

El destinatario de la intimación será el autor de la infracción de la Ley de secretos empresariales, ya sea una persona física o jurídica. Mediante la intimación judicial se requerirá al demandado para que cumpla con la orden judicial correspondiente.

7. Ruiz de la Fuente (2011). 
Ahora bien, también puede darse que sea un tercero de buena fe quien haya adquirido las mercancías objeto de la infracción o documentos u otros soportes que infrinjan los secretos empresariales protegidos por la ley. En este supuesto, si queremos que se vea afectado por la intimación judicial, es necesario que el tercero de buena fe sea también demandado en el proceso declarativo correspondiente. Entendemos que no sería suficiente una simple notificación vía art. 150.3 LEC. La intimación judicial estará dirigida al propio tercero de buena fe como demandado, según se desprende del propio art. 9.7 de la Ley 1/2019.

Pero, en este caso del tercero de buena fe, las medidas objeto de las acciones dispuestas en el apartado 1 del art. 9 podrán sustituirse por el pago de una indemnización pecuniaria a favor de la actora, siempre que dicho pago sea suficientemente satisfactorio y la ejecución de las medidas supongan un perjuicio desproporcionado para el tercero de buena fe demandado. En todo caso, el legislador dispone que la indemnización pecuniaria que sustituya la cesación o prohibición no exceda al importe que habría tenido que pagar al titular del secreto empresarial por la concesión de una licencia que habría permitido utilizarlo durante el período en el que su utilización hubiera podido prohibirse (art. 9.7 Ley 1/2019).

La petición de sustitución deberá ser efectuada por e tercero de buena fe en su contestación a la demanda. Esta parece ser la voluntad del legislador ya que el propio art. 9.7 de la Ley 1/2019 refiere que quien tiene esta capacidad de sustitución es el «demandado». La economía procesal también aboga por esta opción. Esto implica que no cabe dejar esta petición de sustitución para un juicio posterior, una vez exista la sentencia que establezca la intimación. Y también excluye que sea solicitada en ejecución de sentencia por el tercero de buena fe demandado. Recordemos que será necesario discutir que se dan los presupuestos para la sustitución y la cuantía de la indemnización, lo que es propio de un declarativo.

Si no se sustituye en la sentencia, en caso de incumplimiento, en ejecución de sentencia, lo que deberá hacer el demandado tercero de buena fe es cumplir con la intimación judicial o abonar la indemnización coercitiva si no cumple en el marco de una ejecución no dineraria. Si en sentencia se sustituye la intimación por la indemnización, en cambio, y el tercero de buena fe no cumple voluntariamente con el contenido de la intimación judicial, deberá instarse una ejecución dineraria ya que aquí se tratará de una condena al pago de una cantidad de dinero exclusivamente.

\subsection{Notificación}

La notificación de la intimación judicial por vulneración de secretos empresariales no tendrá mayores complejidades, pues al estar contenida en la propia sentencia será notificada junto con ella en la forma prevista en la ley.

No obstante, hay que precisar que eventualmente, además de los apremios económicos dispuestos en la ley y que se pueden imponer en caso de incumplimiento de la intimación judicial, el requerido también podría incurrir en responsabilidad penal por un delito de desobediencia a la autoridad (art. 556 CP). Este tema lo abarcaremos más adelante; no obstante, cabe mencionar ahora que, para que exista responsabilidad penal, es necesario que la intimación judicial sea notificada de forma personal al requerido mediante la entrega de una copia literal de la resolución, o bien mediante la entrega de esta a través de correo, que deberá ser certificado y con acuse de recibo. De lo contrario, el requerimiento tendrá que ser reiterado en sede penal ${ }^{8}$.

\subsection{Plazo}

La existencia de plazo para cumplir dependerá del contenido concreto de la intimación de que se trate. Generalmente, si la intimación impone una prohibición de determinados actos o conductas, o la cesación de determinada actividad, el cumplimiento será exigible en forma automática desde la notificación, por lo que no existirá plazo para cumplir.

No obstante, el tribunal podrá imponer al infractor aquella obligación de cesación o prohibición, pero limitada a cierto período de tiempo. Dicha duración, que será precisada en la intimación, deberá ser, en todo caso, suficiente para eliminar cualquier ventaja competitiva o económica que el infractor hubiera podido extraer de la violación del secreto (art. 9.4 Ley 12/2019).

8. Ver apartado 3.7 
Si la intimación obliga a la realización de conductas positivas como la aprehensión o entrega de mercancías infractoras, documentos y medios destinados a la producción de aquellas, la intimación deberá contener un plazo concreto para que se produzca el cumplimiento voluntario. El plazo será fijado por el tribunal y dependerá de las particularidades del caso concreto, pero siempre deberá ser un plazo breve, en vistas a la celeridad del proceso y de la eficacia de la propia intimación.

En principio, el plazo establecido será improrrogable, salvo que el demandado destinatario de la intimación justifique, debida y oportunamente, que necesita una prórroga del plazo para dar el cumplimiento debido a la orden judicial. Es decir, antes de que el plazo establecido en la sentencia concluya. En cualquier caso, entendemos que esta prórroga solo debiera proceder en casos muy excepcionales, con una justificación contundente y acreditada, y por causas no imputables al demandado condenado.

\subsection{Contenido}

En las intimaciones judiciales el órgano judicial debe precisar en forma directa y concreta en qué consiste la obligación que ha de cumplir el demandado. En su resolución el tribunal habrá concretado cuál es la información que se considera secreto empresarial, así como dónde se encuentra contenida dicha información.

Para determinar qué medidas se van a adoptar para protección de los secretos empresariales, el tribunal deberá tener en consideración la proporcionalidad y las circunstancias del caso concreto, y entre ellas el valor y características del secreto empresarial en cuestión, las medidas que ya se hubieren adoptado para su protección, el comportamiento del infractor, las consecuencias de la violación del secreto empresarial, la probabilidad de que el infractor persista en la violación, los intereses legítimos de las partes, las consecuencias que podrían tener para las partes que se estimen o no las acciones ejercitadas, los intereses legítimos de terceros, el interés público y la salvaguarda de los derechos fundamentales (art. 9.3 Ley 1/2019).

La obligación podrá consistir en cesar determinada conducta o actividad, o en la prohibición de realizar ciertas conductas o actividades que según la sentencia constituyan una violación del secreto empresarial (art. 9.1.b) Ley 1/2019).
Además, la intimación puede contener una prohibición expresa de fabricar, ofrecer, comercializar o utilizar mercancías infractoras; o bien una prohibición de importación, exportación o almacenamiento de estas (art. 9.1.c) Ley 1/2019).

Asimismo, puede disponerse una orden de aprehensión de las mercancías infractoras, incluida la recuperación de las que se encuentren en el mercado, y de los medios destinados únicamente a su producción, siempre que tal recuperación no menoscabe la protección del secreto comercial en cuestión, con una de las siguientes finalidades: su modificación para eliminar las características que determinen que las mercancías sean infractoras, o que los medios estén destinados únicamente a su producción, su destrucción o su entrega a entidades benéficas (art. 9.1.d) Ley 1/2019).

También puede contener una orden de remoción que comprenda la entrega al demandante de todo o parte de los documentos, objetos, materiales, sustancias, ficheros electrónicos o cualesquiera otros soportes que contengan secreto empresarial; y en su caso la destrucción total o parcial de ellos (art. 9.1.e) Ley 1/2019).

Por último, la intimación puede contener la obligación de atribuir en propiedad las mercancías infractoras al demandante. En este caso, la ley dispone que el valor de las mercancías entregadas podrá imputarse al valor de la indemnización de daños y perjuicios debida, sin perjuicio de la subsistencia de la responsabilidad del infractor en lo que dice relación con la cuantía indemnizatoria que exceda del referido valor. Si finalmente el valor de las mercancías excede del importe de la indemnización, el demandante deberá compensarlo a la otra parte (art. 9.1.f) Ley 1/2019).

En este caso, lo más razonable es que el actor proponga el valor que se le ha de atribuir a aquellas mercancías, teniendo en consideración su precio en el mercado. Si no hubiere acuerdo entre las partes, no quedará más remedio que acudir a un peritaje para fijarlo.

Si el infractor condenado no cumple con la orden de entregar las mercancías, se deberá instar la correspondiente ejecución, y en ella incluso se podrá dictar una orden de entrada y registro en el lugar donde se encuentre la cosa, para poner al ejecutante en posesión de aquellas merca- 
derías. Si fuera preciso, se podrá pedir auxilio a la fuerza pública para ello. Si, por el contrario, se desconoce dónde se encuentra la mercadería, deberán instarse las medidas de localización pertinentes para hallarlas, según lo que ha previsto el art. 701 de la LEC para la ejecución de la entrega de bienes muebles determinados. Lo mismo ocurrirá con la orden de remoción que no se cumple voluntariamente por parte del infractor; al respecto, puede ser necesaria en ejecución la orden de entrada y registro, y una vez removidas las mercaderías, archivos u otros documentos, podrán destruirse por un tercero a costa del infractor ejecutado, en los mismos términos que una ejecución de hacer no personalísimo.

Con todo, hay que tener en cuenta que estas acciones no son en absoluto incompatibles entre síi, por lo que se pueden pedir conjuntamente siempre que sean necesarias y proporcionadas.

\subsection{Apercibimiento}

Un punto clave en la efectividad de las intimaciones es que estas se hagan bajo el apercibimiento de las sanciones que se le pueden imponer al destinatario en caso de que incumpla con su obligación. El apercibimiento tiene una doble función: por un lado, constituye una presión psicológica para el destinatario, ya que se le hace saber las consecuencias que se derivarían de su negativa a cumplir, por lo que en definitiva comporta un incentivo para hacerlo. Por otro lado, es una garantía de seguridad jurídica para el demandante, quien, en caso de incumplimiento por parte del infractor condenado, podrá solicitar de inmediato la aplicación de los apremios correspondientes, sin que este último pueda alegar desconocimiento. Para cumplir los cometidos mencionados, es imprescindible que el tribunal especifique en términos precisos las consecuencias del no cumplimiento. Estudiamos a continuación los dos apremios que podrán formar parte del apercibimiento y su ejecución: la indemnización coercitiva y la responsabilidad penal.

\subsection{Apremio económico: la indemnización coercitiva}

Si el infractor destinatario de la intimación incumple la obligación impuesta en la misma, el primer apremio será económico y consistirá en el pago de una cantidad de dinero como «indemnización coercitiva». La imposición de este tipo de apremios económicos constituye una novedad importante introducida por la Ley de secretos empresariales, aunque es un mecanismo que ya está vigente en otros ámbitos de nuestro ordenamiento jurídico. Por ejemplo, la Ley de marcas 17/2001 de 7 de diciembre, en su art. 44, prevé que, cuando se condene a la cesación de los actos de violación de una marca, el tribunal fije una indemnización coercitiva de cuantía no inferior a los 600 euros por día transcurrido hasta que se produzca la cesación de la violación ${ }^{10}$. En este ámbito, la jurisprudencia ha establecido en forma explícita que no causa ningún tipo de indefensión el hecho de que en el fallo de la sentencia se fije el importe concreto de la indemnización coercitiva, luego en ejecución de sentencia se fijará el dies a quo ${ }^{11}$.

Como hemos dicho, la imposición judicial de dicha indemnización coercitiva está dirigida a hacer efectiva la ejecución de las condenas no dinerarias, es decir, busca doblegar la voluntad del infractor, por lo que tendrán una naturaleza coercitiva y no meramente sancionadora ${ }^{12}$. En efecto, el propio legislador las denomina «indemnización

9. En este sentido, Gascón (2018, pág. 1).

10. La doctrina valora positivamente la indemnización coercitiva prevista en el art. 44 de la Ley de marcas, por reforzar la seguridad jurídica y la eficacia de las sentencias judiciales (Castán, 2016). Otros ejemplos de imposición de apremios económicos en el proceso civil español pueden verse en Ruiz de la Fuente (2011, pág. 330).

11. STS 302/2016 de 9 de mayo (RJ 2016\2463); SAP de Valencia de 3 de junio de 2010 (sección 9.a) 743/2016 de 17 de junio (AC 2016\1452).

12. En el ámbito de la indemnización coercitiva prevista en el art. 44 de la Ley de marcas, la Audiencia Provincial de Alicante se refiere expresamente a la finalidad de aquella, y sostiene: «La indemnización coercitiva tiene como finalidad, una vez que los términos de la condena de cesación de los actos de violación de una marca son claros (...), incitar al ejecutado, que voluntaria y conscientemente los ignora, a respetarlos. Exige, pues, una conducta conscientemente reticente al cumplimiento del fallo condenatorio, en lo que respecta a cesar en Ios actos de violación de marca ajena», AAP de Alicante (sección 8. a) 120/2015 de 8 de octubre de 2015 (FJ $2 .^{\circ}$ ). Por su parte, el AAP de Granada (sección 3.a) 208/2017 de 12 de diciembre, analiza ampliamente la indemnización coercitiva del art. 44 de la Ley de marcas, y sostiene en su fundamento jurídico $4 .{ }^{\circ}$ ): «No estamos en presencia de una multa sancionadora sino de una indemnización coercitiva, fijada 
coercitiva». El legislador quiso reforzar con aquella nomenclatura su naturaleza coercitiva y dejar zanjado quién será destinatario de aquella cuantía ${ }^{13}$. Contrariamente a lo que ocurre con las multas que la LEC prevé en ciertos casos similares (por ejemplo, art. 589.3 LEC para la manifestación de bienes del ejecutado, art. 591.2 LEC para la colaboración de terceros en la investigación patrimonial art. 699 LEC para el incumplimiento del requerimiento de cumplimiento con la sentencia en la ejecución no dineraria), en los que se utiliza el término «multa», la indemnización coercitiva prevista en el art. 9.6 de la Ley 1/2019 está concebida como una indemnización de perjuicios en su naturaleza, por lo que será en beneficio del actor. Es un incentivo muy poderoso para su efectiva exigencia ya que el propio actor se beneficia directamente, lo que contribuye al fin de esta consecuencia, según lo exige la Directiva $2016 / 943$.
Por la naturaleza jurídica de la indemnización coercitiva y por su configuración legal, esta es acumulable a otras indemnizaciones de perjuicios que pudieran tener lugar a favor del demandante conforme a las normas generales. El propio art. 9.6 de la Ley 1/2019 lo dispone en estos términos. En ningún caso podríamos hablar de una «doble indemnización» pues la indemnización general prevista en el art. 9 g) y 10 de la Ley 1/2019 tendrá lugar cuando el infractor del secreto empresarial haya incurrido en dolo o culpa, y deberá ser adecuada a la lesión realmente sufrida como consecuencia de la infracción. Para fijarla el tribunal tendrá en cuenta el lucro cesante, el enriquecimiento injusto e incluso elementos no económicos, como el daño moral. En cambio, la indemnización coercitiva tiene por finalidad el cumplimiento de la orden judicial, y encuentra su causa en su incumplimiento y no en la propia vulneración del secreto empresarial14.

en sentencia para el caso de incumplimiento de la obligación de cesar en el uso de la marca después del plazo de cumplimiento voluntario, sin que la ley oblique a realizar un examen de la conducta del condenado incumplidor ni un análisis de si su actuación se ha movido en parámetros de buena o mala fe. No debe confundirse las indemnizaciones coercitivas con las "multas coercitivas", reguladas en los arts. 710 y 711 LEC. Las primeras tienen, en principio, una naturaleza "indemnizatoria" y lo que se obtenga por ellas irá a parar al patrimonio del perjudicado. Las segundas, por el contrario, son de naturaleza sancionatoria de carácter público, y, en consecuencia, lo que se ingrese por ellas está destinado a las arcas públicas. Además, la indemnización coercitiva podría ser renunciada por quien tiene que recibirla, cosa que no sucede con las multas, y también podría ser satisfecha de una manera no personalista, lo que con las multas tampoco sucede. Por otra parte, esta indemnización coercitiva se prevé exclusivamente para el caso de condena judicial a la cesación de los actos de violación, y el condenado incumpla el mandato judicial.

No obstante, del art. 44 de la LM parece inducirse que su naturaleza es mixta. Es decir, de una parte tiene una naturaleza indemnizatoria, de modo que, recibida una cantidad por este concepto, el titular del derecho de marca (salvo que acredite un daño mayor) nada podrá pedir en concepto de indemnización de los daños y perjuicios que pueda causarle el uso ilegítimo del signo distintivo después del dictado de la sentencia firme, y ello con independencia de la indemnización de daños y perjuicios a que se refiere el art. 43 de la LM (que procede por los daños causados antes de la sentencia y responde a otros conceptos). Pero, de otra parte, esta indemnización es coercitiva, es decir, punitiva y disuasoria, en el sentido de que, para recibir una cantidad por este concepto, el perjudicado no estará obligado a acreditar daño alguno. Se establece en favor del titular de derecho de marca por una conducta del infractor del derecho de marca en fase ejecutiva, consistente en permanecer en el uso ilegítimo de la marca después de haberse dictado sentencia en su contra prohibiendo dicho uso y ordenándosele el cese en el mismo.

Este tipo de "indemnizaciones" están justificadas por el hecho de que no es infrecuente en estos sectores económicos que los beneficios obtenidos por el infractor sean superiores a los daños que puedan causar a los titulares de los derechos ilegítimamente utilizados. En cualquier caso, su naturaleza indemnizatoria es preponderante con respecto a su naturaleza punitiva-disuasoria, por lo que no es procedente realizar el examen de la conducta del infractor o juicio de culpabilidad que preconiza la parte apelante».

13. Con esto la Ley $1 / 2019$ se diferencia de otros supuestos legales que prevén multas en un proceso civil, en donde explicita que el destinatario de estas será el erario público, por ejemplo en la ejecución de condenas no dinerarias (art. 711.2 LEC).

14. La AAP de Granada (sección 3.a) 208/2017 de 12 de diciembre, respecto de la indemnización coercitiva del art. 44 de la Ley de marcas, sostiene su incompatibilidad con otras indemnizaciones de la LM o cuanto menos establece límites temporales para una y otra: la sentencia puede indemnizar por daños hasta la sentencia y la indemnización coercitiva será la indemnización para después de la sentencia, sin que quepa otra: «No obstante, del art. 44 de la LM parece inducirse que su naturaleza es mixta. Es decir, de una parte tiene una naturaleza indemnizatoria, de modo que, recibida una cantidad por este concepto, el titular del derecho de marca (salvo que acredite un daño mayor) nada podrá pedir en concepto de indemnización de los daños y perjuicios que pueda causarle el uso ilegítimo del signo distintivo después del dictado de la sentencia firme, y ello con independencia de la indemnización de daños y perjuicios a que se refiere el art. 43 de la LM (que procede por los daños causados antes de la sentencia y responde a otros conceptos)». No cabe realizar la misma interpretación en el ámbito de la Ley de secretos empresariales ya que expresamente se prevé su compatibilidad. Es decir, nada impide que la sentencia disponga una indemnización por lucro cesante que dependa del número de productos vendidos por el demandado, sea antes o después 
En cuanto a la cuantía de la indemnización coercitiva, el legislador solo precisa que deberá consistir en una cantidad líquida y que será una cantidad diaria por día transcurrido hasta que se produzca el total cumplimiento. Para fijar la cuantía el tribunal deberá tener en cuenta las circunstancias del caso concreto; al respecto, la ley habla de «adecuada a las circunstancias» (art. 9.6 Ley 1/2019). La Directiva 2016/943 exigía que fuera «proporcionada» y «disuasoria».

Para facilitar la tarea del tribunal, lo ideal hubiera sido que el legislador fuese más preciso, indicando por ejemplo unos criterios concretos y unos parámetros mínimos a partir de los cuales pudiera moverse el tribunal. Por ejemplo, en el caso mencionado de las violaciones a las marcas, la ley sí que establece un límite mínimo: no podrá ser inferior a los 600 euros. En el caso de las obligaciones de hacer o no hacer, la LEC prevé multas mensuales del $20 \%$ del valor de la cosa o una multa única del 50\% (art. 711.1 LEC). En el caso de acciones de cesación para la defensa de intereses colectivos o difusos, se impondrá una multa que oscilará entre 600 y 60.000 euros por día de retraso en la ejecución de la resolución judicial en el plazo señalado en la sentencia, según la naturaleza y el daño producido y la capacidad económica del condenado (art. 711.2 LEC).

Por lo tanto, el tribunal fijará la cuantía de la indemnización coercitiva líquida y diaria atendiendo a las circunstancias del caso concreto. La falta de mayor detalle en la concreción de los criterios y cuantías mínimas puede suplirse acudiendo a los fines de esta indemnización coercitiva y los propios parámetros que la Ley 1/2019 prevé para las medidas que tiene que adoptar el juez (art. 9.3 Ley 1/2019). La cuantía de la multa debe ser disuasoria para el infractor, es decir, debe tener una cuantía suficiente para que desincentive el incumplimiento de la intimación judicial, por lo que creemos que el tribunal deberá tener en considera- ción, entre otros aspectos, a la hora de fijarla, el valor del secreto empresarial en cuestión, la entidad o consecuencias del daño provocado para el actor, el comportamiento del infractor y la probabilidad de que este persista en su violación, los intereses de terceros y los generales, pero también la capacidad económica del infractor condenado, que la Ley 1/2019 no menciona, lógico en este ámbito si el fin es disuasorio, y que por lo demás la LEC contempla en ámbitos similares (por ejemplo el art. 711 LEC). Si la cuantía de la indemnización coercitiva no tiene en consideración estos aspectos, perderá su eficacia y no tendrá el carácter «proporcionado» y la fuerza «disuasoria» que le exige la directiva.

La cuantía de la indemnización coercitiva deberá ser objeto de discusión en el proceso declarativo y de determinación concreta en la sentencia que contenga la intimación. Esta es la aparente voluntad del legislador que deriva de la configuración que se hace en el art. 9.6 Ley 1/2019. En caso de omisión por error, se podría plantear el posible complemento de la sentencia para llevar a efecto su cumplimiento, según el art. 215 LEC. No parece en cambio que pudiera ser objeto de solicitud de concreción dentro de la propia ejecución.

Si el demandado infractor persiste en su contumacia frente a la intimación ${ }^{15}$, la exigencia del apremio económico podrá hacerse efectivo por el demandante mediante la correspondiente demanda de ejecución no dineraria en que se podrá liquidar la cantidad debida como indemnización coercitiva hasta la fecha de la misma demanda, y en ella pedir que la cuantía de la ejecución se amplíe para cubrir los sucesivos incumplimientos de la multa periódica establecida en la sentencia, según lo dispuesto en el art. 578 LEC (art. 9.6 Ley 1/2019), no siendo necesarios nuevos requerimientos ${ }^{16}$. El ejecutante podrá también pedir en la demanda ejecutiva los

de la sentencia, junto con una intimación de cesar en la venta de los productos, con una indemnización coercitiva de tanto por día. Como veremos, esta indemnización coercitiva en la Ley de secretos empresariales se fija según la ley por parámetros que son distintos, aunque pueden coincidir parcialmente con el daño sufrido por el titular del secreto.

15. En el AAP de Alicante 120/2015 de 8 de octubre, el tribunal valora la actitud del condenado a la hora de apreciar la viabilidad de la indemnización coercitiva prevista en el art. 44 de la Ley de marcas, considerando esencial la concurrencia de una «conducta conscientemente reticente al cumplimiento del fallo condenatorio». La audiencia deja sin efecto la indemnización coercitiva en este caso por considerar que la actitud del condenado/ejecutado fue diligente, que no pudo cumplir con el contenido de la orden judicial por razones ajenas a su voluntad y que, además, tuvo una actitud tendente a evitar la producción de perjuicios a la otra parte (titular de la marca).

16. En este sentido se ha manifestado AAP de Granada (sección 3.a) 208/2017 de 12 de diciembre, en el ámbito de la Ley de marcas: «No cabe establecer la necesidad de un nuevo requerimiento al ejecutado para que cumpla el contenido de la sentencia y en caso negativo proceder a hacer efectiva la indemnización coercitiva, sino que esta cobró virtualidad desde el momento en el que el ejecutado dejó de cumplir los 
embargos de garantía con un alcance suficiente para cubrir el importe liquidado y sus sucesivas ampliaciones (art. 700 LEC).

\subsection{Apremio personal: la responsabilidad penal}

Por otra parte, y a pesar de que la ley no lo dice expresamente, el infractor que ha sido requerido para cumplir con determinada acción o abstención a través de la correspondiente intimación judicial, y que no cumple con el contenido de esta ni se justifica debidamente, podría incurrir en responsabilidad penal por desobediencia a la autoridad, prevista en el art. 556 CP.

Hay que tener en cuenta que la responsabilidad penal en sede civil debe ser el último recurso, sin dejar de reconocer que las medidas personales pueden ofrecer ciertas ventajas, como poder aplicarse a cualquier deudor, con independencia de su titularidad sobre algún bien o su liquidez, por ejemplo. Además, coadyuvan a desarrollar la idea en virtud de la cual el proceso no es solo un instrumento de realización del derecho, sino que también presta un servicio público que debe garantizarse cumpliendo con parámetros de eficacia y rentabilidad ${ }^{17}$.
Por lo tanto, si un infractor incumple con la orden judicial contenida en la intimación judicial, primero se le han de aplicar los apremios económicos dispuestos en la ley, esto es, la multa o indemnización coercitiva. Pero si, a pesar de la imposición de dicha multa, esta no es efectiva y el infractor se niega a cumplir y se resiste a realizar lo ordenado en la intimación judicial, entonces se podrá perseguir al contumaz por un delito de desobediencia a la autoridad en sede penal. Esto podrá hacerse simultáneamente a la exigencia del apremio económico; no hay necesidad alguna de optar y no se excluyen ambos tipos de consecuencia.

Ahora bien, como ya apuntábamos anteriormente, para hacer efectiva la responsabilidad penal la jurisprudencia exige que haya existido una orden judicial expresa, terminante y clara, y que se haya puesto en conocimiento del acusado por medio de un requerimiento formal, personal y directo. Además, es necesario que haya una resistencia por parte del requerido a cumplir con lo que se le ordena. En otras palabras, se trata de que exista una verdadera actitud omisiva, pertinaz y clara de resistencia a cumplir con lo ordenado ${ }^{18}$.

Por tanto, en caso de falta de cumplimiento voluntario con la resolución judicial, el actor podrá solicitar en la demanda ejecutiva no dineraria que se requiera al deman-

términos del fallo condenatorio en el plazo que se le concedió en la propia sentencia, con independencia de que se le pueda requerir para el cumplimiento de los otros pronunciamientos contenidos en el fallo en el plazo a que se refiere el art. 699 de la LEC» (FJ 2. ${ }^{\circ}$ ).

17. En este sentido, Armenta Deu (2015, pág. 26).

18. Es reiterada la jurisprudencia del Tribunal Supremo en la que se establece que, para que se configure responsabilidad penal por desobediencia a la autoridad, es necesario que haya existido una orden judicial expresa terminante y clara que informe de las consecuencias de su incumplimiento y que haya sido puesta en conocimiento del destinatario mediante un requerimiento formal personal y directo, a fin de que se pueda acreditar que el destinatario ha tenido conocimiento efectivo de la orden. Además, tiene que haber una resistencia a cumplir con dicha orden. Ver STS 13 de junio de 2000 [RJ 2000।6597], 25 de febrero de 1994 [RJ 1994\566], 13 de diciembre y 16 de marzo de 1993 [RJ 1993\9421 y RJ 1993\2311], y 15 de febrero de 1990 [RJ 1990\1548]); STS de 18 de abril de 1997 [RJ $1997 \backslash 2991]$, entre otras. Más recientemente podemos mencionar, por ejemplo, Ia SAP de Las Palmas (sección 6. a) 192/2019 de 16 de julio (JUR 2019 \264481), en la que el tribunal reconoce que la vía civil (el art. 589 LEC en relación con los arts. 153 y 28.4) permite la notificación por medio de procurador pues no se requiere que la notificación del requerimiento sea personal, si bien ello no presupone que dicha norma despliegue sus efectos iqualmente en la vía penal, cuando el delito imputado necesita del cumplimiento de unos requisitos que no se ajustan a los requisitos civiles, siendo reiterada la doctrina y jurisprudencia, que establece que uno de los requisitos imprescindibles es el requerimiento formal, personal y directo, es decir, es necesario un requerimiento personal, en la vía de ejecución en este caso, para poder fundamentar una condena de desobediencia a la autoridad. En el mismo sentido, la SAP de Burgos (sección 1. a) 32/2020 de 21 de enero (JUR2020 3105132 ) refuerza la importancia del apercibimiento y de la actitud contumaz del incumplidor, sosteniendo que: «En consecuencia, adquiere especial trascendencia en el ámbito penal la existencia de un apercibimiento previo, a modo de requerimiento preciso, claro, expreso y terminante de las consecuencias penales que la vulneración del mandato u orden puede generar en el eventual incumplidor. Por otra parte, es preciso para la comisión del delito de desobediencia que haya un mandato persistente y reiterado de modo que frente a él quede de manifiesto una actitud de oposición tenaz y obstinada, que es lo que constituye la esencia de esta infracción penal, unido a la existencia de un dolo específico de escarnecer el principio de autoridad» (FJ 2.․). (La cursiva es nuestra.) Ver también, SAP de Madrid de 11 de febrero de 2003 (JUR2003/200745); SAP de Córdova de 11 de mayo de 2004 (JUR2004/199653); y SAP de Álava de 23 de marzo de 2005 (JUR2004/288236). 
dado para que cese en su conducta (art. 699 LEC), bajo el apercibimiento de responsabilidad penal. Podrá y deberá reiterarse el requerimiento dentro de la ejecución a fin de que, de mantenerse el demandado en su conducta, se alcancen los requisitos que exige la jurisprudencia penal para la comisión del delito de desobediencia. Y una vez hecho esto, el actor podrá pedir la deducción de testimonio de los particulares de la ejecución a fin de interponer las correspondientes acciones penales.

\section{Conclusiones}

El secreto empresarial tiene hoy una nueva regulación sustantiva y procesal. Junto con unas nuevas acciones, que pueden dar lugar a requerimientos, se regulan algunas consecuencias del incumplimiento como es la indemnización coercitiva. La intención del legislador sin duda es buena; sin embargo, como hemos analizado, deja muchos aspectos en el aire, lo que puede poner en jaque su aplicación efectiva.

Es menester mencionar algunos puntos en los que la transposición de la directiva por el legislador español hubiera podido ser mejor.

En primer lugar, se podría haber evitado la dispersión normativa que provoca la utilización de una ley específica para regular las especialidades procesales relativas a la protección del secreto empresarial. Sin duda, las previsiones sobre las intimaciones y sus consecuencias, además de otras normas en la materia, se hubiesen podido incorporar a la LEC para mantener la unidad legislativa procesal, contribuyendo a la seguridad jurídica.

En segundo lugar, el legislador no ha aprovechado todos los avances de la ciencia procesal ya que se ha limitado a regular fragmentariamente algunas consecuencias procesales del incumplimiento de las resoluciones judiciales dirigidas a proteger el secreto empresarial. Ante este panorama, la pretensión del presente artículo ha sido reconstruir la intimación judicial en materia de secretos empresariales, para poder alcanzar los fines de la norma.

En tercer lugar, el legislador, aunque ha optado por una figura como la indemnización coercitiva, dotada de alta eficacia, no ha resuelto todos los problemas a que pueda dar lugar su aplicación, algunos de los cuales ya se han puesto de relieve en ámbitos en que también está prevista. También podría haber contribuido aún más a su efectividad fijando los criterios para su concreción y un importe mínimo, bien por cuantía o porcentaje.

En cuarto lugar, la responsabilidad penal por incumplimiento de la intimación judicial dictada para proteger un secreto empresarial queda sometida a los mismos obstáculos que su exigencia en otros ámbitos. Podría quizá decirse que la sanción prevista por el legislador en este caso no es suficientemente efectiva como exigía la directiva.

En fin, aunque es importante que la ley contemple instrumentos procesales, lo es más que estos se apliquen de forma rápida y efectiva. La intimación judicial es una herramienta legal, disponible, que puede ser muy ágil y económica. Para maximizar su eficacia y garantizar el cumplimiento de las resoluciones judiciales adoptadas en este ámbito, los tribunales deben hacer una aplicación sin vacilaciones, ni dilaciones ni reiteraciones innecesarias. Se trata de garantizar la seguridad jurídica con el fin último de mejorar las condiciones, el marco para el desarrollo y la explotación de la innovación y la transferencia de conocimientos. 


\section{Referencias bibliográficas}

ARMENTA DEU, T. (2015). «Ejecución y medidas conminativas personales. Un estudio comparado». Revista de Derecho, Universidad Católica del Norte (Chile), vol. 22, núm. 2, pág. 23-54 [en línea] http://dx.doi.org/10.4067/S0718-97532015000200002 [Fecha de consulta: 28 de septiembre de 2020].

ARMENTA DEU, T. (2018). «Medidas coercitivas dirigidas a tutelar el desarrollo adecuado del proceso y a colaborar con la justicia. Una aproximación comparada». Derecho y proceso. Liber amicorum Francisco Ramos Méndez. Barcelona: Atelier, vol. I, págs. 299-322.

ARROYO APARICIO, A. (2019). «Secretos empresariales en el ordenamiento español, transposición de la Directiva 2016/943». Revista Aranzadi Doctrinal, núm. 11, pág. 5.

CASTÁN, A. (2016). «Indemnización coercitiva por incumplimiento de sentencia condenatoria por infracción de una marca comunitaria». Comentario de sentencia [en línea] https:/elderecho. com/indemnizacion-coercitiva-por-incumplimiento-de-sentencia-condenatoria-por-infraccion-demarca-comunitaria [Fecha de consulta: 28 de septiembre de 2020.]

GARCÍA VIDAL, Á. (2019). «Diez cuestiones clave sobre la Ley de secretos empresariales». Análisis, pág. 2 [en línea] https://www.gap.com/wp-content/uploads/2019/02/Analisis-Secretos-empresariales_def.pdf [Fecha de consulta: 28 de septiembre de 2020].

GASCÓN, F. (2018). «Hacia una mayor protección jurídica de los secretos empresariales». Actualidad Jurídica Aranzadi, núm. 943 (versión electrónica).

ORTELLS RAMOS, M. (2004). «¿Multas o astricciones? Una indefinición de la Nueva Ejecución Forzosa Española». Revista Internauta de Práctica Jurídica, núm. 13, págs. 1-23.

PROTOCOLO DE PROTECCIÓN DEL SECRETO EMPRESARIAL EN LOS JUZGADOS MERCANTILES (2019). Sección de Derecho de la Competencia, Tribunal Mercantil de Barcelona [en línea] https://www. oepm.es/export/sites/oepm/comun/documentos_relacionados/Noticias/2019/2019_11_22_ProtocoIo_Proteccion_Secreto_Empresarial_en_los_JM.pdf [Fecha de consulta: 28 de septiembre de 2020.]

RUIZ DE LA FUENTE, C. (2011). Las intimaciones judiciales en el proceso civil. Barcelona: Atelier. 


\section{Cita recomendada}

RUIZ DE LA FUENTE, Consuelo (2020). «Las intimaciones judiciales en la Ley de secretos empresariales». IDP. Revista de Internet, Derecho y Política, núm. 32 (marzo). UOC [Fecha de consulta: dd/mm/aa] http://dx.doi.org/10.7238/idp.v0i32.373743

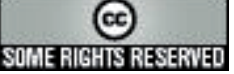

Los textos publicados en esta revista están -si no se indica lo contrario- bajo una licencia Reconocimiento-Sin obras derivadas 3.0 España de Creative Commons. Puede copiarlos, distribuirlos y comunicarlos públicamente siempre que cite su autor y la revista y la institución que los publica (IDP. Revista de Internet, Derecho y Política; UOC); no haga con ellos obras derivadas. La licencia completa se puede consultar en: http://creativecommons.org/ licenses/by-nd/3.0/es/deed.es.

\section{Sobre la autora}

Consuelo Ruiz de la Fuente

consuelo.ruiz.delafuente@uab.cat

Doctora en Derecho, es profesora de Derecho Procesal en la Universidad Autónoma de Barcelona y profesora colaboradora en la Universitat Oberta de Catalunya.

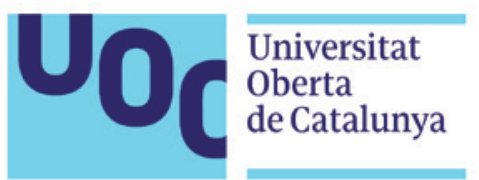

